\title{
Atividade alelopática de folhas e pseudofrutos de Hovenia dulcis Thunb. (Rhamnaceae) sobre a germinação de Lactuca sativa L. (Asteraceae)
}

\author{
Alana Cristina Dorneles Wandscheer ${ }^{1,2}$, Junior Borella ${ }^{1}$, Luziana Cassol Bonatti ${ }^{1}$ e Lindamir Hernandez Pastorini
}

Recebido em 12/05/2009. Aceito em 3/12/2010

\begin{abstract}
RESUMO
(Atividade alelopática de folhas e pseudofrutos de Hovenia dulcis Thunb. (Rhamnaceae) sobre a germinação de Lactuca sativa L. (Asteraceae)). Neste trabalho, objetivou-se avaliar o efeito alelopático de folhas secas e pseudofrutos de Hovenia dulcis Thunb. sobre sementes de alface. Para isso, prepararam-se extratos aquosos de folhas e pseudofrutos nas concentrações 1,2 e $4 \%$ (m/v). Realizou-se quatro repetições de 25 sementes de alface, distribuídas em placas de Petri forradas com papel Germitest e umedecidas com os extratos, mantidas em câmara de germinação à temperatura de $25^{\circ} \mathrm{C}$, fotoperíodo constante e presença de luz por cinco dias, sendo o controle água destilada. Calculou-se a porcentagem, a velocidade, o índice de velocidade de germinação, o comprimento radicular e da parte aérea das plântulas, bem como o efeito das sementes na presença de diferentes soluções de pH. Observou-se que as plântulas foram significativamente afetadas na presença de extratos aquosos de folhas secas e pseudofrutos nas concentrações 2 e $4 \%$. Os efeitos foram desvinculados do $\mathrm{pH}$ e potencial osmótico, indicando, portanto, interferência alelopática dos extratos obtidos de Hovenia dulcis.
\end{abstract}

Palavras-chave: alelopatia, alface, extratos aquosos, Hovenia dulcis

\begin{abstract}
(Allelopathic activity of Hovenia dulcis Thunb. (Rhamnaceae) leaves and pseudofruits on the germination of Lactuca sativa L. (Asteraceae)). This paper aims to evaluate the allelopathic effect of dry leaves and pseudofruits of Hovenia dulcis Thunb. on lettuce seeds. Therefore, aqueous extracts of leaves and pseudofruits were prepared in $1 \%, 2 \%$ and $4 \%(\mathrm{~m} / \mathrm{v})$ concentrations. Four replicates were done of 25 lettuce seeds distributed in Petri dishes lined with Germitest paper and humidified with the extracts, maintained in germination chamber at $25^{\circ} \mathrm{C}$, constant photoperiod and light presence for five days, the control being distilled water. The percentage, speed, germination rate index, root length and aerial-part length of the seedlings were calculated, as well as the seeds effect in the presence of different $\mathrm{pH}$ solutions. It was observed that the seedlings were significantly affected in the presence of aqueous extracts of dry leaves and pseudofruits at $2 \%$ and $4 \%$ concentrations. The effects were not linked to $\mathrm{pH}$ and osmotic potential, indicating, therefore, allelopathic interference of Hovenia dulcis extracts.
\end{abstract}

Key words: allelopathy, lettuce, aqueous extracts, Hovenia dulcis

\section{Introdução}

A alelopatia é um processo natural em que determinada planta produz compostos químicos que, quando liberados no ambiente, podem inibir ou estimular o desenvolvimento de outros organismos (Rice 1984). Casos de alelopatia observados na natureza são tão antigos que a 5 a.C Theophrastus, por exemplo, já mencionava o efeito negativo de vegetais sobre as características químicas do solo (Gliessman 2000; Souza \& Furtado 2002).
Os aleloquímicos são substâncias finais ou intermediárias do metabolismo secundário vegetal, biossintetizadas a partir de compostos originados do metabolismo primário (Rice 1984). Os mais comuns pertencem ao grupo dos ácidos fenólicos, cumarinas, terpenóides, flavonoides, alcaloides, glicosídeos cianogênicos, derivados do ácido benzóico, taninos e quinonas (Ferreira \& Aquila 2000; King \& Ambika 2002). Segundo Rizvi et al. (1992), é quase impossível enumerar cada um dos compostos hoje considerados alelopáticos, devido à grande diversidade $\mathrm{e}$

\footnotetext{
Universidade Regional Integrada do Alto Uruguai e das Missões. Departamento de Ciências Biológicas, Frederico Westphalen, RS, Brasil

2 Autor para correspondência: alanacdw@hotmail.com
} 
quantidade. Entre as rotas de liberação incluem-se a volatilização, lixiviação, tecidos vegetais em decomposição ou exsudação do sistema radicular (Medeiros \& Lucchesi 1993; Rodrigues et al.1999).

Os efeitos alelopáticos podem variar quanto à sua intensidade, visto que a ação dos aleloquímicos é condicionada por diversos fatores, tais como solo, concentração, temperatura e condições hídricas (Macías et al. 2007; MaraschinSilva \& Aquila 2005). Uma vez introduzidos no ambiente, é necessário o acúmulo destes compostos em quantidades suficientes para que possam afetar outras plantas, além de se manterem por determinado tempo ou serem liberados continuamente, para que os efeitos sejam persistentes (Rodrigues et al. 1999).

As alterações visíveis sobre a germinação e o crescimento de plântulas causadas por substâncias alelopáticas são somente manifestações de efeitos primários ocorridos ao nível molecular (Rizvi et al. 1992). Tais alterações podem resultar em feitos sobre a permeabilidade de membranas, transcrição e tradução do DNA, o funcionamento dos mensageiros secundários, a respiração, fotossíntese, a conformação de enzimas e de receptores ou ainda pela combinação destes fatores (Ferreira \& Aquila 2000). Assim, a vegetação de uma determinada área pode ter um modelo de sucessão condicionado às plantas preexistentes e às substâncias químicas que elas liberaram no meio, conforme seu tempo de residência (Chou 1999; Ferreira \& Borghetti 2004).

A inibição da germinação de plântulas e o crescimento destas estão frequentemente associados à efeitos alelopáticos, sendo um processo importante nas interações vegetais em ambientes naturais e agroecossistemas (Fritz et al. 2007). Para Ferreira \& Aquila (2000), a germinação é menos sensível aos aleloquímicos do que o crescimento da planta, pois para cada semente o fenômeno é discreto, germinando ou não.

Em estudos de alelopatia, a utilização de cipselas de alface são freqüentes, por serem sensíveis à ação dos aleloquímicos, apresentando inibição dose-dependente, como em trabalho verificado por Wandscheer \& Pastorini (2008).

Outro aspecto que deve ser considerado em experimentos alelopáticos é o controle do $\mathrm{pH}$ e da concentração de extratos brutos, pois pode haver nestes substâncias como açúcares, aminoácidos, ácidos orgânicos, entre outros, que podem mascarar o efeito alelopático por influenciar na concentração iônica e ser osmoticamente ativos (Ferreira \& Aquila 2000; Ferreira \& Borghetti 2004), pois alterarem a propriedade da água resultando numa pressão osmótica diferente de zero na solução (Villela et al. 1991).

$\mathrm{O}$ desejo crescente de substituir os insumos químicos sintéticos nos agroecossistemas por materiais produzidos naturalmente motivou uma explosão de pesquisas aplicada à alelopatia (Gliessman 2000). Isto porque os benefícios da pesquisa alelopática podem ser utilizados para melhorar a sustentabilidade de nossos sistemas de produção e a conservação da vegetação natural ou seminatural (Chou
1999; Macías et al. 1998; Olofsdotter \& Mallik 2001; Smith \& Martin 1994). Souza Filho et al. (2006) sugerem que substâncias químicas com atividade alelopática podem ser utilizadas diretamente na formulação de bioerbicidas ou serem modificadas com vistas a aumentar sua atividade biológica. Em vista disso, diversos trabalhos têm sido desenvolvidos para estudar compostos químicos vegetais com potencial alelopático (Chaves et al. 2001; Cunico et al. 2006; Fujii et al. 2003; Kato-Noguchi et al. 1998; Kong et al. 2004; Macías et al. 2006).

Hovenia dulcis Thunb. (Rhamnaceae) é uma planta originária da China e do Japão, mas atualmente muito difundida em todo o Sul do Brasil, principalmente em propriedades agrícolas. É uma árvore de porte alto e crescimento rápido que apresenta grande plasticidade. De suas raízes foram isolados três alcalóides peptídicos: hovenia A, hovenia B e frangulamina, além de saponinas em suas raízes e também presentes nas sementes (Carvalho 1994). Visto ser uma espécie exótica com grande habilidade adaptativa, é bastante utilizada também para recuperação de áreas degradadas e reflorestamento ciliar de açudes (Carvalho 1994). Mundeleski et al. (2008) observaram a tendência da espécie em formar agrupamentos, sendo visível o número de plântulas que se estabelecem próximo a indivíduos adultos, podendo impedir o desenvolvimento de espécies nativas.

Este fato somado à capacidade desta espécie em formar populações densas e dominantes, torna necessário a investigação do potencial alelopático dessa espécie, sendo esta, uma possível estratégia que contribui no estabelecimento dessas populações. Neste contexto, o objetivo da presente pesquisa foi verificar possível ação alelopática de extratos aquosos de folhas secas e pseudofrutos de Hovenia dulcis Thunb. (Rhamnaceae) sobre sementes de Lactuca sativa L. (Asteraceae).

\section{Material e métodos}

Folhas e pseudofrutos (pedúnculos frutíferos) de Hovenia dulcis Thunb. (Rhamnaceae) foram coletados em áreas de vegetação próximos à Universidade Regional Integrada do Alto Uruguai e das Missões (URI), município de Frederico Westphalen, RS, Brasil, nas coordenadas geográficas $27^{\circ} 36^{\prime} 08.91^{\prime \prime}-27^{\circ} 21^{\prime} 38.88^{\prime \prime}$ e e $53^{\circ} 40^{\prime} 49.65^{\prime \prime}-53^{\circ} 24^{\prime} 17.87^{\prime \prime} \mathrm{W}$, em maio e junho de 2008.

Após coleta, o material vegetal foi levado ao Laboratório de Fisiologia Vegetal da URI, onde prepararam-se extratos aquosos de folhas e pseudofrutos em três concentrações: 1,2 e $4 \%(1,2$ e 4 g de material vegetal / $100 \mathrm{~mL}$ de água destilada $(\mathrm{m} / \mathrm{v}))$, sendo utilizado material vegetal seco para a preparação de extratos foliares e material vegetal fresco para extratos de pseudofrutos.

Para a obtenção do material vegetal seco, folhas de uva-do-japão foram deixadas secar à temperatura ambiente por um período aproximado de sete dias, abrigados da luz 
direta e umidade (Oliveira et al. 2004). Na preparação dos extratos, as partes vegetais foram pesadas separadamente em balança analítica, sendo em seguida, maceradas em almofariz juntamente com $30 \mathrm{~mL}$ de água destilada. Posteriormente, acrescentou-se $70 \mathrm{~mL}$ de água destilada e a mistura permaneceu em repouso durante $24 \mathrm{~h}$ (no escuro e sob refrigeração $\pm 10^{\circ} \mathrm{C}$ ). Decorrido este período, os extratos foram filtrados em algodão hidrófilo e acondicionados em vidros tampados e mantidos em congelador até o momento de serem utilizados.

Como espécie alvo utilizou-se sementes (cipselas) de alface (Lactuca sativa L. cv. "Grand rapids") os quais foram obtidos no comércio local. Os testes foram realizados em placas de Petri $(9 \mathrm{~cm}$ de diâmetro) forradas com duas folhas de papel Germitest (esterilizadas) e umedecidas com aproximadamente $5 \mathrm{~mL}$ dos extratos. Cada placa foi composta por 25 sementes distribuídas aleatoriamente, havendo quatro repetições para cada tratamento, mais o tratamento controle (água destilada). As sementes permaneceram nas placas de Petri após a germinação, sendo mantidas em câmara de germinação B.O.D. à temperatura de $25^{\circ} \mathrm{C}$, fotoperíodo constante e presença de luz por um período de cinco dias, através de quatro lâmpadas brancas fluorescentes de $25 \mathrm{~W}$, do tipo luz do dia. Segundo Bravin et al. (2006) a irradiância média de duas lâmpadas equivale a $30 \pm 5 \mathrm{~m}^{-2} \mathrm{~s}^{-1}$. O papel Germitest foi mantido úmido por meio de regas com os extratos, quando necessário. Todas as concentrações de extrato foram caracterizadas quanto ao $\mathrm{pH}$, aferido com pHmetro (Tecnal) e potencial osmótico estimado pelo método de Chardakov (Salisbury \& Ross 1992).

Para a germinação de sementes, boas condições de umidade, luminosidade e temperatura são indispensáveis para determinar o potencial máximo de germinação (Brasil 2009). Para ensaios realizados em placas de Petri, a radícula deve apresentar no mínimo 50\% do tamanho da semente ou diásporo, sendo este o critério usual para a germinação. No presente trabalho utilizou-se a curvatura geotrópica da raiz como critério para o início da contagem da germinação, sendo os dados verificados diariamente (Ferreira \& Aquila 2000).

Com os dados obtidos nos bioensaios, foram calculados ao final dos experimentos de germinação, a porcentagem, velocidade e o índice de velocidade de germinação (Vieira \& Carvalho 1994). Para verificar o efeito dos extratos aquosos de uva-do-japão sobre o crescimento inicial das plântulas de alface, foram também avaliadas variáveis como o comprimento radicular e da parte aérea das plântulas recém formadas (a análise de crescimento procedeu-se a partir das plântulas germinadas do experimento de germinação). O comprimento radicular e da parte aérea foi obtido de 10 plântulas por placa, totalizando 40 plântulas por tratamento, decorridos cinco dias da instalação do experimento (Borella \& Pastorini 2009). As variáveis foram avaliados com auxílio de papel milimetrado e a unidade de medida usada o centímetro $(\mathrm{cm})$ (Wandscheer \& Pastorini 2008).
Para descartar a possibilidade de interferência do $\mathrm{pH}$ dos extratos de uva-do-japão, realizaram-se testes de germinação de sementes de alface sob a influência de soluções de pH três, cinco, sete, nove e onze, sendo as sementes mantidas sob as mesmas condições e analisadas sob os mesmos parâmetros a que foram submetidas quando tratadas com extratos aquosos de folhas e pseudofrutos da espécie doadora. Para obtenção das soluções de $\mathrm{pH}$, foram adicionados hidróxido de potássio $(\mathrm{KOH})$ ou ácido clorídrico $(\mathrm{HCl})$ à água destilada em quantidades suficientes para elevar ou baixar o pH da solução, sendo a aferição realizada com pHmetro (Mayeux \& Scifres 1978).

O delineamento experimental foi inteiramente casualizado com seis tratamentos e um controle e quatro repetições por tratamento. Nos bioensaios de germinação de sementes de alface sob a influência de diferentes concentrações de $\mathrm{pH}$, utilizaram-se cinco tratamentos e três repetições por tratamento. Todos os resultados foram submetidos à ANOVA e comparados pelo teste de Tukey a $1 \%$ de probabilidade com o uso do Programa Estat - Sistema para Análises Estatísticas (V. 2,0) UNESP - Jaboticabal.

\section{Resultados e discussão}

Com base nos resultados obtidos após os experimentos, observou-se que extratos aquosos de pseudofrutos nas concentrações 2 e $4 \%$ produziram efeitos inibitórios significativos na porcentagem de germinação de sementes de alface, sendo que na maior concentração houve inibição da germinação (Tab. 1). Do mesmo modo, extratos de folhas secas (2 e 4\%) reduziram significativamente a porcentagem de germinação das sementes, em relação ao tratamento controle (Tab. 2). Borella \& Pastorini (2009) verificaram que extratos aquosos de folhas de umbu inibiram significativamente a germinação de sementes de tomate e picão-preto, sendo maior o efeito quanto maior a concentração do extrato. Do mesmo modo, extratos aquosos provenientes de folhas de Aristolochia esperanzae O. Kuntze inibiram a germinação de sementes de alface (Gatti et al. 2004) em testes laboratoriais. Oliveira et al. (2009), ao analisar os efeitos alelopáticos de frutos de juazeiro sobre sementes de alface verificaram inibição da germinação para as maiores concentrações dos extratos, semelhante ao observado na presente pesquisa.

Considerando a velocidade de germinação das sementes de alface, pode-se observar uma redução significativa causada pelo extrato de pseudofruto a $2 \%$ (Tab. 1) e folha seca a $4 \%$ (Tab. 2). Cunico et al. (2006) observaram que concentrações de extrato bruto e substâncias isoladas das raízes de Ottonia martiana Miq. (Piperaceae) não apresentaram influência sobre a germinação de sementes de alface, porém, promoveram um forte atraso neste processo. Segundo Periotto et al. (2004) extratos de caules e folhas de Andira humilis Mart. ex Benth reduziram significativamente a porcentagem e a velocidade de germinação de sementes de alface e rabanete, em relação ao controle, indicando interferência alelopática desta espécie. 
Tabela 1. Efeito de diferentes concentrações de extratos aquosos de pseudofrutos de Hovenia dulcis Thunb. sobre a porcentagem de germinação (G), velocidade de germinação (VG), índice de velocidade de germinação (IVG), comprimento radicular e da parte aérea de plântulas de alface (Lactuca sativa L.).

\begin{tabular}{|c|c|c|c|c|c|}
\hline Tratamentos & $\begin{array}{c}G \\
(\%)\end{array}$ & $\begin{array}{c}\text { VG } \\
\text { (dias) }\end{array}$ & $\begin{array}{c}\text { IVG } \\
\text { (plânt./dia) }\end{array}$ & $\begin{array}{l}\text { Comp. Radicular } \\
(\mathrm{cm})\end{array}$ & $\begin{array}{c}\text { Comp. Parte aérea } \\
(\mathrm{cm})\end{array}$ \\
\hline Controle & $98 \mathrm{a}^{*}$ & $1,2 \mathrm{~b}$ & $22,4 \mathrm{a}$ & $5,5 \mathrm{a}$ & $2,6 \mathrm{a}$ \\
\hline $1 \%$ & $98 \mathrm{a}$ & $1,2 \mathrm{~b}$ & $21,3 \mathrm{a}$ & $4,6 \mathrm{a}$ & $1,7 \mathrm{~b}$ \\
\hline $2 \%$ & $21 \mathrm{~b}$ & $2,3 \mathrm{a}$ & $3,2 \mathrm{~b}$ & $0,8 \mathrm{~b}$ & $0,7 \mathrm{c}$ \\
\hline $4 \%$ & $0 \mathrm{c}$ & - & - & - & - \\
\hline
\end{tabular}

* Médias seguidas pela mesma letra não diferem, em cada variável, pelo teste de Tukey a 1\% de probabilidade de erro. (-) análise não realizada.

Tabela 2. Efeito de diferentes concentrações de extratos aquosos de folhas secas de Hovenia dulcis Thunb. sobre a porcentagem de germinação (G), velocidade de germinação (VG), índice de velocidade de germinação (IVG), comprimento radicular e da parte aérea de plântulas de alface (Lactuca sativa L.).

\begin{tabular}{lccccc}
\hline Tratamentos & $\mathrm{G}$ & $\mathrm{VG}$ & $\begin{array}{c}\text { IVG } \\
(\%)\end{array}$ & $\begin{array}{c}\text { Comp. Radicular } \\
(\mathrm{cm})\end{array}$ & $\begin{array}{c}\text { Comp. Parte aérea } \\
(\mathrm{cm})\end{array}$ \\
\hline Controle & $98 \mathrm{a}^{*}$ & $1,5 \mathrm{~b}$ & $19,9 \mathrm{a}$ & $2,9 \mathrm{a}$ & $1,1 \mathrm{~b}$ \\
$1 \%$ & $96 \mathrm{a}$ & $1,7 \mathrm{~b}$ & $18,2 \mathrm{ab}$ & $3,1 \mathrm{a}$ & $2,3 \mathrm{a}$ \\
$2 \%$ & $85 \mathrm{~b}$ & $1,9 \mathrm{~b}$ & $13,2 \mathrm{bc}$ & $1,1 \mathrm{~b}$ & $1,4 \mathrm{~b}$ \\
$4 \%$ & $79 \mathrm{~b}$ & $2,6 \mathrm{a}$ & $8,4 \mathrm{c}$ & $0,8 \mathrm{~b}$ & $1,3 \mathrm{~b}$ \\
\hline
\end{tabular}

* Médias seguidas pela mesma letra não diferem, em cada variável, pelo teste de Tukey a $1 \%$ de probabilidade de erro.

Com relação ao número de plântulas germinadas por dia (IVG), observou-se uma significativa redução para este parâmetro em sementes de alface sob a influência de extratos aquosos de pseudofrutos a $2 \%$ (Tab. 1) bem como extratos de folhas secas nas concentrações 2 e $4 \%$ (Tab. 2). Extratos aquosos de folhas de umbu nas concentrações $2 \%$ e $4 \%$ inibiram o IVG de sementes de alface e picão-preto em testes de laboratório (Borella \& Pastorini 2009). Inibições deste parâmetro também foram constatadas em sementes de alface e tomate submetidas a extratos aquosos de folhas e raízes de Raphanus raphanistrum (Wandscheer \& Pastorini 2008). Borella et al (2009) ao analisar os efeitos de extratos aquosos de folhas frescas e secas do abacateiro sobre sementes de alface observaram inibição da germinação e crescimento inicial das plântulas.

Medeiros \& Lucchesi (1993) ao analisar os efeitos alelopáticos da parte aérea da ervilhaca (Vicia sativa L.) sobre sementes de alface, constataram que os extratos foram mais ativos nas maiores concentrações, ocorrendo inclusive oxidação e morte das sementes. Do mesmo modo, extratos de folhas secas de $H$. dulcis causaram deformações e necroses nas plântulas de alface. As plântulas que se desenvolveram apresentaram epicótilos mais grossos que as plântulas submetidas ao tratamento controle. Segundo Ferreira \& Aquila (2000), algumas substâncias alelopáticas podem induzir o aparecimento de plântulas anormais, sendo a necrose da radícula um dos sintomas mais comuns.

Quanto ao comprimento radicular e da parte aérea, observou-se que extratos aquosos de pseudofrutos a $2 \%$ reduziram significativamente o comprimento radicular de plântulas de alface e concentrações de extratos $1 \%$ e $2 \%$ reduziram também o comprimento da parte aérea das plântulas, em relação ao tratamento controle (Tab. 1). Concentrações 2 e $4 \%$ de extratos de folhas secas também inibiram o comprimento radicular das plântulas de alface, em relação ao tratamento controle. Para o comprimento da parte aérea, não houve reduções significativas das plântulas de alface submetidas aos extratos aquosos de folhas secas de uva-do-japão, em relação ao controle (Tab. 2).

Souza Filho et al. (2005) observaram que substâncias presentes em folhas de Parkia pendula (Leguminosae) apresentaram efeito sobre o desenvolvimento radicular de plântulas de malícia e mata-pasto e que tais efeitos estiveram positivamente associados à concentração das substâncias. Da mesma forma, Correia et al. (2005) ao analisar o efeito de extratos aquosos de sorgo sobre sementes de soja, perceberam que estes não interferiram na porcentagem ou velocidade de germinação das sementes, no entanto, causaram efeitos significativos sobre o comprimento radicular das plântulas, quando comparados ao controle.

Outro importante aspecto a ser considerado é que os efeitos sobre sementes de alface foram mais significativos quanto maior a concentração do extrato sejam eles de pseudofruto ou folha seca. Diversos autores também constataram efeito dose/dependente, ao analisar a alelopatia de outras espécies (Gatti et al. 2004; Souza Filho et al. 2006). Também influenciaram no aparecimento de plântulas anormais, com disparidades no tamanho estrutural, com raízes primárias atrofiadas e defeituosas e ausência de raízes secundárias, efeitos aparentemente comuns, segundo (Chon et al. 2000), pelo fato de as raízes serem mais sensíveis às substâncias presentes nos extratos quando comparados às demais estruturas das plântulas. Isso poderia ocorrer 
também pelo contato direto e prolongado das raízes com os extratos (aleloquímicos) em relação à parte aérea (Chung et al. 2001) e/ou um reflexo da fisiologia distinta entre as estruturas (Aquila et al. 1999).

O potencial osmótico dos extratos de $H$. dulcis variaram entre -0,085 e -0,017 MPa (Tab. 3), sendo descartada a hipótese de interferência deste fator nos resultados. Para Gatti et al. (2004) os valores de potencial osmótico não podem ultrapassar $-0,2 \mathrm{MPa}$, pois podem apresentar determinados solutos que alteram a propriedade da água, resultando numa pressão osmótica diferente de zero na solução (Villela et al 1991).

Os valores de $\mathrm{pH}$ variaram entre 6,65 e 3,94 (Tab. 3). Sendo que extratos de pseudofrutos 2 e $4 \%$ apresentaram baixos valores de $\mathrm{pH}$, objetivou-se descartar a possível interferência deste fator realizando bioensaios de germinação de sementes de alface sob a influência de diferentes soluções de pH. Após os experimentos, pode-se observar que nenhuma solução interferiu negativamente nos parâmetros analisados (Tab. 4). Eberlein (1987), Mayeux \& Scifres (1978) e Roy (1986) sugerem que apenas valores de extrema acidez (abaixo de três) ou extrema alcalinidade (acima de 11) podem interferir no processo germinativo, o que pode ser observado no presente trabalho.

Em testes preliminares (dados não publicados) a atividade alelopática de folhas frescas de uva-do-japão também foi verificada, no entanto, os resultados demonstraram que extratos aquosos de folhas frescas não apresentaram efeitos sobre a germinação de sementes de alface. Detecção de grupos químicos em folhas frescas, secas e pseudofrutos de uva-do-japão foram verificados, apenas qualitativamente. Nestas análises houve presença de saponinas, flavonóides e alcalóides nas partes vegetais analisadas.

Após a investigação desses fatores, fortalece-se a idéia de que a queda das folhas e dos pseudofrutos da uva-do-japão e a eventual substituição das mesmas no ambiente, além de auxiliar no enriquecimento dos solos, poderia liberar neste substâncias alelopáticas capazes de impedir o estabelecimento de outras plantas próximas à ela, visto que Hovenia dulcis é espécie caducifólia e extratos de folhas secas causaram significativos efeitos sobre sementes de alface. Entretanto, para confirmação dessa hipótese são necessários outros experimentos, que visem à obtenção de resultados a campo, já que os dados obtidos referem-se a testes laboratoriais.

Com os resultados da presente pesquisa pode-se concluir que os efeitos verificados sobre a germinação e crescimento de sementes de alface são ocasionados pelo potencial alelopático de Hovenia dulcis Thunb.

\section{Agradecimentos}

À Universidade Regional Integrada do Alto Uruguai e das Missões (URI), Campus de Frederico Westphalen, pela concessão da bolsa de Iniciação Científica e infra-estrutura necessária à realização da pesquisa e a todos que contribuíram para a realização deste trabalho.

Tabela 3. Características físico-químicas dos extratos aquosos de folhas secas e pseudofrutos de Hovenia dulcis Thunb. utilizados nos bioensaios para verificação de atividade alelopática.

\begin{tabular}{|c|c|c|c|}
\hline Extrato & Concentração (p/v) \% & $\mathrm{pH}$ & $\psi_{\mathrm{s}}^{*}(\mathrm{MPa})$ \\
\hline & Controle & 7,0 & 0,000 \\
\hline \multirow[t]{3}{*}{ Pseudofruto } & 1 & 5,49 & $-0,017$ \\
\hline & 2 & 4,15 & $-0,021$ \\
\hline & 4 & 3,94 & $-0,058$ \\
\hline \multirow[t]{3}{*}{ Folha seca } & 1 & 6,65 & $-0,024$ \\
\hline & 2 & 6,56 & $-0,042$ \\
\hline & 4 & 5,98 & $-0,085$ \\
\hline
\end{tabular}

${ }^{*} \psi_{s}:$ potencial osmótico.

Tabela 4. Efeito de diferentes soluções de potencial hidrogeniônico (pH) sobre a porcentagem de germinação (G), velocidade de germinação (VG), índice de velocidade de germinação (IVG), comprimento radicular e da parte aérea de plântulas de alface (Lactuca sativa L.).

\begin{tabular}{|c|c|c|c|c|c|}
\hline Tratamentos & $\begin{array}{c}\mathrm{G} \\
(\%)\end{array}$ & $\begin{array}{c}\mathrm{VG} \\
\text { (dias) }\end{array}$ & $\begin{array}{c}\text { IVG } \\
\text { (plânt./dia) }\end{array}$ & $\begin{array}{c}\text { Comp. Radicular } \\
(\mathrm{cm})\end{array}$ & $\begin{array}{c}\text { Comp. Parte aérea } \\
(\mathrm{cm})\end{array}$ \\
\hline pH 3 & $96 \mathrm{a}^{*}$ & $1,0 \mathrm{a}$ & $23,6 \mathrm{a}$ & $2,1 \mathrm{~b}$ & $0,8 \mathrm{ab}$ \\
\hline pH 5 & $98,6 \mathrm{a}$ & $1,0 \mathrm{a}$ & $23,9 \mathrm{a}$ & $2,1 \mathrm{~b}$ & $0,7 \mathrm{~b}$ \\
\hline pH 7 & $97,3 \mathrm{a}$ & $1,0 \mathrm{a}$ & $23,8 \mathrm{a}$ & $2,0 \mathrm{~b}$ & $0,8 \mathrm{ab}$ \\
\hline pH 9 & $94,6 \mathrm{a}$ & $1,0 \mathrm{a}$ & $23,0 \mathrm{a}$ & $3,0 \mathrm{a}$ & $0,8 \mathrm{~b}$ \\
\hline pH 11 & $97,3 \mathrm{a}$ & $1,0 \mathrm{a}$ & $24,1 \mathrm{a}$ & $2,3 \mathrm{~b}$ & $0,9 \mathrm{a}$ \\
\hline
\end{tabular}

* Médias seguidas pela mesma letra não diferem, em cada variável, pelo teste de Tukey a 1\% de probabilidade de erro. 


\section{Referências bibliográficas}

Aquila, M.E.A.; Ungaretti, J.A.C. \& Michelin, A. 1999. Preliminary observation on allelopathic activity in Achyrocline satureoides (Lam.) DC Acta Horticulturae 502: 383-388.

Borella, J. \& Pastorini, L.H. 2009. Influência alelopática de Phytollaca dioica L. na germinação e crescimento inicial de tomate e picão-preto. Biotemas 22(3): 67-75.

Borella, J.; Wandscheer, A.C.D.; Bonatti, L.C. \& Pastorini, L.H. 2009. Efeito alelopático de extratos aquosos de Persea americana Mill. Sobre Lactuca sativa L. Revista Brasileira de Biociências 7(3): 260-265.

Brasil. Ministério da Agricultura, Pecuária e Abastecimento. 2009. Regras para Análise de Sementes. Brasília, Secretaria de Defesa Agropecuária. Mapa/ACS.

Bravin, I.C.; Valentin, Y.Y. \& Yokoya, N.S. 2006. Formação de calos e regeneração de segmentos apicais de Hypnea musciformis (Wulfen) Lamouroux (Gigartinales, Rhodophyta): obtenção de culturas axênicas e efeitos da concentração do ágar. Revista Brasileira de Botânica 29(1): 175-182.

Carvalho, P.E.R. 1994. Ecologia, silvicultura e usos da uva-do-japão (Hovenia dulcis Thunberg.). Colombo, EMBRAPA - CNPFlorestas.

Chaves, N.; Sosa, T. \& Escudero, J.C. 2001. Plant growth inhibiting flavonoids in exudate of Cistus ladanifer and in associated soils. Journal of Chemical Ecology 27(3): 623-631.

Chon, S.U.; Coutts, J.H. \& Nelson, C.J. 2000. Effects of light, growth media, and seedling orientation on bioassays of alfalfa autotoxicity. Agronomy Journal 92(4): 715-720.

Chou, C.H. 1999. Roles of allelopathy in plant biodiversity and sustainable agriculture. Critical Reviews in Plant Sciences 18(5): 609-630.

Chung, I.M.; Ahn, J.K. \& Yun, S.J. 2001. Assessment of allelopathic potential of barnyard grass (Echinochloa crus-gall) on rice (Oriza sativa L.) cultivars. Crop Protection 20(10): 921-928.

Correia, N.M.; Centurion, M.A.P.C. \& Alves, P.L.C.A. 2005. Influência de extratos aquosos de sorgo sobre a germinação e o desenvolvimento de plântulas de soja. Revista Ciência Rural 35(3): 498-503.

Cunico, M.M.; Dias, J.G.; Miguel, M.D.; Miguel, O.G.; Auer, C.G.; Côcco, L.C.; Lopes, A.R.; Yamamoto, C.I. \& Monache, F.D. 2006. Potencial antimicrobiano e alelopático das amidas isoladas do extrato das raízes de Ottonia martiana Miq. Química Nova 29(4): 746-749.

Eberlein, C.V. 1987. Germination of Sorghum almum seeds and longevity in soil. Weed Science 35(6): 796-801.

Ferreira, A.G. \& Aquila, M.E.A. 2000. Alelopatia: uma área emergente da ecofisiologia. Revista Brasileira de Fisiologia Vegetal 12 (Edição Especial): 175-204.

Ferreira, A.G. \& Borghetti, F. 2004. Germinação: do básico ao aplicado. Porto Alegre, Artmed.

Fritz, D.; Bernardi, A.P.; Hass, J.S.; Ascoli, B.M.; Bordignon, S.A. de L. \& Poser, G.V. 2007. Germination and growth inhibitory effects of Hypericum myrianthum and $H$. polyanthemum extracts on Lactuca sativa L. Brazilian Journal of Pharmacognosy 17(1): 44-48.

Fujii, Y.; Parvez, S.S.; Parvez, M.M.; Ohmae, Y. \& Iida, O. 2003. Screening of 239 medicinal plant species for allelopathic activity using the sandwich method. Weed Biology and Management 3: 233-241.

Gatti, A.B.; Perez, S.C.J.G.A. \& Lima, M.I.S. 2004. Atividade alelopática de extratos aquosos de Aristolochia esperanzae O. Kuntze na germinação e no crescimento de Lactuca sativa e Raphanus sativus L. Acta Botanica Brasilica 18(3): 459-472.

Gliessman, S.R. 2000. Agroecologia: processos ecológicos em agricultura sustentável. 2 ed. Porto Alegre, Universidade/UFRGS.

Kato-Noguchi, H.; Kosemura, S. \& Yamamura, S. 1998. Allelopathic potential of 5-chloro-6-methoxy-2-benzoxazolinone. Phytochemistry 48(3): 433-435.

King, S.R. \& Ambika, R. 2002. Allelopathic plants. 5. Chromolaena odorata (L.). Allelopathy Journal 9(1): 35-41.

Kong, C.; Xu, X.; Zhou, B.; Hu, F.; Zhang, C. \& Zhang, M. 2004. Two compounds from allelopathic rice accession and their inhibitory activity on weeds and fungal pathogens. Phytochemistry 65(8): 1123-1128.
Macías, F.A.; Fernández, A.; Varela, R.M.; Molinillo, J.M.G.; Torres, A. \& Alves, P.L.C.A. 2006. Sesquiterpene lactones as allelochemicals. Journal of Natural Products 69(5): 795-800.

Macías, F.A.; Molinillo, J.M.G.; Varella, R.M. \& Galindo, J.C.G. 2007. Allelopathy - a natural alternative for weed Control. Pest Management Science 63(4): 327-348.

Macías, F.A; Varela, R.M.; Torres, A.; Oliva, R.M. \& Molinillo, J.M.G. 1998. Bioactive norsesquiterpenes from Helianthus annuus with potential allelopathic activity. Phytochemistry 48(4): 631-636.

Maraschin-Silva, F. \& Aquila, M.E.A. 2005. Potencial alelopático de Dodonaea viscosa (L.) Jacq. Iheringia 60(1): 91-98.

Mayeux, H.S. \& Scifres, C.J. 1978. Germination of goldenweed seed. Journal of Range Management 31(5): 371-374.

Medeiros, A.R.M. de. \& Lucchesi, A.A. 1993. Efeitos alelopáticos da ervilhaca (Vicia sativa L.) sobre a alface em testes de laboratório. Pesquisa Agropecuária Brasileira 28(1): 9-14.

Mundeleski, E.; Schmitz, J.A.K. \& Biondo, E. 2008. Estudo ambiental da microbacia do Arroio Jacarezinho (Nova Boréscia e Encantado/ RS) com ênfase na mata ciliar e na qualidade da água. Caderno de Pesquisa série Biologia 20(3): 44-62.

Oliveira, A.K.de; Diógenes, F.E.P.; Coelho, M. de F.B. \& Maia, S.S.S. 2009. Alelopatia em extratos de frutos de juazeiro (Ziziphus joazeiro Mart. - Rhamnaceae). Acta Botanica Brasilica 23(4): 1186-1189.

Oliveira, S.C.C.; Ferreira, A.G. \& Borghetti, F. 2004. Efeito alelopático de folhas de Solanum lycocarpum A. St. Hil. (Solanaceae) na germinação e crescimento de Sesamum indicum L. (Pedaliaceae) sob diferentes temperaturas. Acta Botanica Brasilica 18(3): 401-406.

Olofsdotter, M. \& Mallik, A.U. 2001. Allelopathy symposium. Agronomy Journal 93(1): 1-2.

Periotto, F.; Peres, S.C.J.G.A. \& Lima, M.I.S. 2004. Efeito alelopático de Andira humilis Mart. ex Benth na germinação e no crescimento de Lactuca sativa L. e Raphanus sativus L. Acta Botanica Brasilica 18(3): 425-430.

Rice, E.L. 1984. Allelopathy. $2^{\text {nd }}$ ed. London, Academic Press.

Rizvi, S.J.H.; Haque, H.; Singh, V.K. \& Rizvi, V. 1992. A discipline called allelopathy. Pp. 1-10. In: Rizvi, S.J.H. \& Rizvi, V. (Eds.). Allelopathy: basic and applied aspects. London, Chapman \& Hall.

Rodrigues, B.N., Passini, T. \& Ferreira, A.G. 1999. Research on allelopathy in Brazil. Pp. 307-323. In: Narwal, S.S. (Eds.). Allelopathy update. New Hampshire, Science Publishers.

Roy, M.M. 1986. Effects of $\mathrm{pH}$ on germination of Dichrostachys cineria (L.). Wegth \& Arn. Journal Tree Science 5(1): 62-64.

Salisbury, F.B. \& Ross, E.W. 1992. Plant Physiology. Belmont, Wadsworth.

Smith, A.E. \& Martin, D.L. 1994. Allelopathic characteristics of three cool-season grass in the forage ecosystems. Agronomy Journal 8(2): 243-246.

Souza, I.F. \& Furtado, D.A.S. 2002. Caracterização de aleloquímicos do centeio (Secale cereale) e seu potencial alelopático sobre plantas de alface (Lactuca sativa). Ciência e Agrotecnologia 26(5): 1097-1099.

Souza Filho, A.P.S.; Borges, F.C. \& Santos, L.S. 2006. Análise comparativa dos efeitos alelopáticos das substâncias químicas titonina e titonina acetilada. Planta Daninha 24(2): 205-210.

Souza Filho, A.P.S.; Fonseca, M.L. \& Arruda, M.S.P. 2005. Substâncias químicas com atividade alelopática presentes nas folhas de Parkia pendula (Leguminosae). Planta Daninha 23(4): 565-573.

Vieira, R.D. \& Carvalho, N.M. 1994. Testes de vigor em sementes. Jaboticabal, FUNEP.

Villela, F.A.; Doni Filo, L. \& Sequeira, E.L. 1991. Tabela de potencial osmótico em função da concentração de polietileno glicol 6.000 e da temperatura. Pesquisa Agropecuária Brasileira 26(11-12): 1957-1968.

Wandscheer, A.C.D. \& Pastorini, L.H. 2008. Interferência alelopática de Raphanus raphanistrum L. sobre a germinação de Lactuca sativa L. e Solanum lycopersicon L. Ciência Rural 38(4): 949-953.

Zhang, Q. 1993. Potential role of allelopathy in the soil and the decomposition root of chinese-fir replant woodland. Plant Soil 151(2): 205-209. 